\title{
Changing youth? Continuities and ruptures in transitions into adulthood among Catalan young people.
}

\author{
Pau Serracant ${ }^{1}$
}

Final version published in: Pau Serracant (2011): Changing youth? Continuities and rupturesin transitions into adulthood among Catalan young people, Journal of Youth Studies,DOI:10.1080/13676261.2011.643234

Sociology Department (Universitat Autònoma de Barcelona) and Catalan Youth Observatory, Barcelona, Spain.

The globalization process has an impact at the micro-level on life-course patterns: concretely, the trajectories of young people into adulthood are being sharply modified. At a European level, the extension, delinearization, reversibility and diversification of youth trajectories have been identified as major changes. However, the extent to which these changes affect young people within each country depends on their respective welfare regimes. This paper analyses how the Mediterranean welfare regime shapes youth trajectories among Catalan young people and explores the hypothesis that these constraints will make those trajectories less sensitive to the general trends of change identified at a European level. The research is based on an analysis of the Catalan Youth Survey, an official statistic that contains retrospective data on

E-mail: pserracant@gencat.cat 
Educational, Work, Housing and Family transitions. The results offer an integrated typology of youth transitions in Catalonia and show how the persistence of traditional patterns of transition are the logical result of the particular articulation of the welfare regime and cultural patterns among Catalan young people.

\section{Keywords}

Youht transitions; life-course; welfare regime; Catalonia; Southern Europe

\section{Introduction}

This paper analyses how the changes in the patterns of transition into adulthood identified at a European level are shaped by the Catalan youth transition regime (Walther 2006) in order to reveal the extent to which these general trends may be assumed with regard to Southern European societies.

Thus, from a European perspective the major social transformations that occurred lasting recent decades (Lipovetsky 1987, Bauman 1992, Castells 1996, Beck 1992, Giddens 1991) have transformed life course patterns (Mayer 2001) and young people -who are, by definition, negotiating their social position- could be expected to be especially sensitive to them.

Discussion of how these changes have influenced youth transition patterns has been broad and often contradictory (Pollock 2008). However, a review of the specialised literature highlights four major axes of change at a European level: the extension (Cavalli and Galland 1993), de-linearization (EGRIS 2001, 2002, Baizán et al 
2002), reversibility (Machado 200, EGRIS 2001) and diversification (Stauber and Walther 2002, 2006) of youth trajectories. .

As could be expected, the institutional filters of each country modulate the extent to which youth trajectories are changed. Esping-Andersen's (1990) welfare regimes usually serve as the basis for the diverse youth transition regimes that have been attempted (Cavalli and Galland, 1995, Walther 2006, Van de Velde 2008). The variation in the patterns of youth transition across Europe may question the assumption, as Roberts et al (2009) do, that the general trends of youth transitions are common to all Western European Societies.

This paper analyses youth transitions in Catalonia, one of the seventeen Autonomous Communitites in Spain. It is an interesting case study, to the extent that it highlights the influence of the Mediterranean welfare regime in an advanced postindustrial society. Particularly, the aims of this research are $a$ ) to build up a typology of trajectories of transition into adulthood among Catalan young people and $b$ ) to analyse the extent to which general European trends on youth transitions are common among them, relating the results to the characteristics of the Mediterranean welfare regime.

Concretely, Catalonia is a region (“Autonomous Community”) of Spain with a high level of political autonomy and a population of 7,504,881 people, 1,300,272 of which (17.3\%) are aged 15-29 (Continuous Population Census, 2009). Catalonia is an example of Ferrara's (1996) "Southern model of welfare", in which a weak welfare state is combined with persistently high unemployment, structural precariousness and an extended black economy in a segmented labour market, all of which makes families more responsible for the individuals' well-being than in other European countries (Alegre 2011). Therefore, strong intergenerational ties and social reproduction tends to be the outcome of this model. 
Van de Velde (2005) argues that in Spain the Mediterranean welfare regime (in which labour market segmentation and weak public policies strengthen family ties) results into the logic of "installing oneself". According to that, young Spanish people do not take risks and wait at their parental home before taking the next step into adulthood. Our hypothesis is that this logic will result in young Catalan people being less affected by the changes in youth transition patterns that have been identified at a European level. Thus, the particular articulation of the welfare regime in Southern societies would be preserving the traditional patterns of transition into adulthood to a greater extent that in other societies.

\section{Changes in youth transitions}

Despite the amplitude of the debate on new youth transition patterns (Pollock 2008), the general trends identified at a European level can be summarised as follows:

- Extension. Since Cavalli and Galland (1993) signalled the extension of the youth phase, much evidence has been found to support their point. From a historical point of view, the youth transition has unequivocally lenghtened during the 20th century, and during the last decades this extension has accelerated, stimulating authors to conceptualize youth as a phase of life more than as a transitional moment (Cavalli and Galland 1993) or even to defend a new period of life- Arnett's emerging adulthood (2000).

- De-linearization. Trajectories of transition into adulthood have also become increasingly non-linear. The idea of a change from linear (rigid) to non-linear 
(flexible) societies underlines the theories of many authors such as the aforementioned Bauman, Beck or Giddens, but it has also reached the field of life course studies (Buchmann 1989) and has been widely used in youth studies ${ }^{\mathrm{i}}$. So, according to the Fordist model of transition, linearity was the dominant feature of the trajectories of transition (Baizán et al 2002). The general sequence started at the end of education followed by rapid insertion in the labour market and finished when the youngster left home and (usually simultaneously) formed his/her own family. Today, the overlapping of study and work, lifelong learning or leaving home before achieving a certain labour market stability have become more frequent.

- Reversibility. Backtracking is one of the mechanisms through which the linearity of transitions has been broken but it can also occur without changing the traditional sequence of sub-transitions. Reversibility implies the return to a stage which, in the linear logic, has been overcome, i.e. returning to formal education or to an unmarried state. It is typical of the post-industrial transition model, in contrast with the Fordist model in which steps tended to be more definitive (Baizán et al 2002). The yo-yo image (Machado 2001, EGRIS 2001) has settled to describe some of the current youth trajectories, characterised by non-linearity and reversibility.

- Diversification. The combination of the three previous phenomena (expansion, delinearization and reversibility of youth trajectories) has widened the scope of pathways that a young person may follow. Thus, from an "old" model of transition in which the types of trajectories individuals followed were few, today young people's possible trajectories seem to be more diverse. Stabuer and Walther (2002, 2006) use the concept of de-standardisation to explain the change from a Fordist 
context marked by predictable standardisation of trajectories to a context in which diversity and unpredictability are the norm.

These changes are closely linked to the general debate on individualization. The destandardisation of transitions means that young people are not linked any more to the old models and securities and now depend, broadly speaking, either on self-reflexive processes (Beck 1992) or on the position of the individual in a polarised social structure (Castel 1995). Beck's work is usually linked to the concept of choice biographies, which might be increasing among young people (Du-Bois Reymond 1995) and would imply that the fracture of linear life course patterns provides young people with more options. But the de-standardisation of trajectories may also mean they are forced to face alone structural constraints that have not moved. Significantly, Furlong and Carmel's (1997) epistemological fallacy of late modernity referred to the objective persistence of structural constraints in a context of "biographical subjectivization" (Leccardi 2006).

\section{General trends... for diverse societies}

The development of these general trends varies throughout Europe, to the extent that they may be almost absent, as Roberts et al (2009) show for the case of some South Caucasian European countries. In order to grasp this variability, Esping-Andersen's (1990) welfare regimes have been used to build up models of youth transition regimes. Cavalli and Galland (1995), Walther (2006), Van de Velde (2005, 2008) or Mills' (2009) models are consistent with each other and show significant variations in youth transitions depending on the institutional context. Both Walther and Van de Velde's models agree to consider cultural differences as a key element for understanding 
regional variations in transitions, in addition to the classical material differences linked to economy and social policies.

Particularly, Van de Velde (2005) shows how the concrete characteristics of each country influence the patterns of transition. Thus, the comprehensive nature of the Nordic regime favours individualisation; the corporate bias of the Continental regime presses young people to "place themselves" into society through a stratified education; the liberal culture and welfare regime of the Anglo-Saxon societies encourage early and risky autonomy; and, finally, major labour market segmentation and weak public policies strengthen family ties in Southern Europe and favour a logic of "installing oneself". Thus, leaving the parent's home would be "the last phase of a process which has three acts: getting a stable job, getting married and buying a house" (op cit: 62).

It therefore makes sense to expect the general trends identified at a European level to be less dominant in Catalonia as a result of the characteristics of its welfare regime. Thus, young people may be expected to follow a linear logic in which steps are thoughtfully taken in order to face a precarious labour market and a weak social protection.

\section{Methodology}

This research is based on an analysis of the 2007 Catalan Youth Survey, a periodical official statistic produced by the Catalan Government aimed at describing the living conditions of young people. The questionnaire, mostly based on present-time questions, includes four groups of retrospective questions on education, employment, housing and family formation. 
The survey universe is comprised of individuals aged from 15 to 34 years who lived in Catalonia in 2007, making a total of 2,060,588 people. The sample size is 2,400 respondents with an error of $+/-2.9(95 \%$ error and $\mathrm{p}=\mathrm{q})$. The research aims to study the full trajectories of young people: consequently, to generate our typology of trajectories we analysed the sub-sample of young people aged 30-34 $(n=574)$. A cluster analysis was used to build the typology of trajectories: to achieve this, it is necessary to select the variables based on which of these groups will be created. Drawing on the main dimensions of transitions from youth to adulthood (i.e. education, employment, housing and family), fifteen representative variables were selected (Table 1).

\section{[TABLE 1 ABOUT HERE]}

Finally, to deepen the analysis of the extent to which extension, de-linearization and reversibility are occurring among young Catalan people, these concepts were measured after creating a variable for each of them (Tables 2, 3 and 4). This methodological approach is inspired by a research carried out by Furlong et al $(2003)^{\mathrm{ii}}$.

\section{A typology of trajectories of transition into adult life}

The data analysis generated a typology of the different ways in which young people in Catalonia 'pass' through the youth life course phase. To produce the clusters we carried out a hierarchical analysis that resulted into seven groups that reflect different types of trajectory and gathers information on the four sub-transitions that form the youth phase. 
Graph 1 shows the proportion of young people included in each of the seven types of trajectory identified.

Graph 1. Types of youth trajectories among the population aged 30-34. Catalonia, 2007.

\section{[GRAPH 1 ABOUT HERE]}

Next each group is described following the cluster analysis logic, i.e. mentioning first the characteristics that appear first in each group's results (those variables that make young people gather in each group, which may be of a different nature in other groups).

- Group I. Late occupation trajectory (11.2\%). Young people who followed this trajectory have a university degree and combine an early housing transition with a certain delay in the accomplishment of the other transitions, especially that of employment: it is in this group where young people start working (as their main activity $^{\mathrm{iii}}$ ) at the latest age (26-29). Despite this delay in entering the labour market, their short professional trajectory is characterised by their occupying qualified jobs and contractual stability. Although those who left home before the age of 30 did so very early, most members of this group are single with no children and pay above average rent. This group has little or no difficulty in making ends meet.

Women are overrepresented in this group as well as those living in bigger cities (more than 50,000 inhabitants). The highest occupational categories are overrepresented among their parents and manual skilled and non-skilled workers are underrepresented; similarly, parents with a higher educational level are also overrepresented. 
- Group II. University precarious trajectory (2.9\%). This minority trajectory gathers university graduates whose employment trajectory has been marked by temporary employment and/or unemployment and carrying out non-skilled jobs (they are, therefore, over-qualified). Like most university graduates they started working full time at age 23-25 and have had a short but quite precarious trajectory in terms of employment. They mostly left home at age 25 to 29 and live in poor quality rented flats. This group has economic difficulties but also a positive opinion about the education they have received.

Again women are overrepresented among this group and the proportion of young people that lives in medium-size cities $(10,000-50,000$ inhabitants) is also above the average. Their parents have a higher level of education than in other groups but both employers and manual non-skilled workers are overrepresented, their most common occupation being that of a clerk.

- Group III. University linear trajectory $(\mathbf{2 3 . 8 \%})$. The trajectory of the young people included in this group is characterised by progression: most of its members completed their university education, then started working and, subsequently, left home to live with their partner and bought their own dwelling. Their professional trajectory is marked by stability and having non-manual qualified occupations in a much higher proportion than average; likewise, unlike most young people, they have no difficulties making ends meet. Their educational trajectory took place in private schools in a higher proportion than average and practically the whole group has a positive or very positive view of the education they received. 
This is the only "university" group in which there are more men than women. Its members mostly live in bigger cities and their social origin (measured through their parents' occupations and educational attainment) is above average.

\section{- Group IV. Post-compulsory secondary education linear trajectory}

(22.2\%). The trajectory of the young people included in this group is similar to that of the previous group (in the sense of a linearity marked by stability) but, due to the shorter length of their educational career, they have taken the next steps at an earlier age: most of these individuals completed their post-compulsory secondary education and then started working (19-22 years old) in qualified or non-qualified occupations, left home and afterwards live with their partners (mainly married) in their own apartment. The proportion of those who have children and who say they have no problems making ends meet is higher than the average.

In this group men are overrepresented, but their place of residence and social origin is fully representative of Catalan society.

- Group V. Living with parents trajectory (17.3\%). The common characteristic of this group is that they have not left home before the age of thirty (and therefore have never lived with their partner). All of the young men and women making up this group are single and have no children. This delay in leaving home and forming their own family is not the result of a lengthy academic career and taking longer to find a job, since almost half of these young people have received the maximum compulsory secondary education and found a job between the ages of 19 and 22 or before that age, and have not suffered many unemployment problems. Certainly, they have had many temporary jobs and worked in lower occupational categories to 
a slightly larger extent than average, but this is largely quite a heterogeneous group with respect to educational and employment transitions in which the fundamental element is the lack of residential independence.

Men are overrepresented in this group and also those young people living in bigger cities. Their social origin is diverse, although parents who are skilled manual workers and have a low educational level are overrepresented.

- Group VI. Working class and separated from partner trajectory (5.7\%). The main characteristic of this group of young people is their housing and family trajectory: they left home at an early age (almost all of them before the age of 25) to live with their partner, and almost half had their first child before they were thirty; but in more than half of cases the couple split up. In this group, those who have abandoned their studies (at public, state-run schools) in order to start working at an early age form the majority, therefore being mostly employed in lower occupations and having suffered above average unemployment.

Women are overrepresented in this group and also young people living in towns (2,000-10,000 inhabitants). Clerks and non-skilled manual workers are overrepresented among their parents as well as those with a low educational level.

- Group VII. Working class trajectories (16.9\%). The young people included in this group abandoned or finished their studies at an early age and then started to work, meaning that they are the group that has worked the highest number of years from 15 to 29 years old. They left home before most young people and started to live in their owned housing with their partner; most of them had their first child 
before thirty. Also, and partly because of their difficult professional trajectory, almost half the members of this group consider it difficult to make ends meet.

Men form the basis of this group, which is also overrepresented in medium-size cities. The social origin of its members is similar to the previous group, but in a more accentuated manner.

To gain a general view of the resulting map, it is important to note that educational variables (together with the age at which young people start working) are those that tend to split young people's trajectories into different types. The first three types of trajectory correspond mainly to university graduates, and diverge with respect to employment. The linear university trajectory shows a clear parallelism with the post-compulsory secondary education linear trajectory, the length of the studies being the main feature that distinguishes between them. On the other hand, among those that had short educational careers (working class trajectory and working class and separated from partner trajectory) the other transitions take place earlier and enjoy a less advantageous position in the labour market.

\section{Changes in youth trajectories}

Now that the typology of trajectories has been summarised, the next step consists of analysing them from the perspective of the general trends identified at a European level. The objective is to verify the extent to which the four changes in youth trajectories described in the first section of this article occur in Catalonia, as an example of a Mediterranean model of welfare regime. To do this, apart from the typology itself, 
some complementary data has been generated concerning the events and sequences within the trajectories of young people.

\section{Extension of trajectories}

Table 2 shows the current extension of youth transitions: the mean age for ending studies (which includes returns to education such as Master degrees, etc.) is 22.0; first occupation (as main activity) occurs at 21.2; leaving home at 25.6; and young people have their first child at 28.2.

\section{[TABLE 2 ABOUT HERE]}

The pace of the transition varies depending on the type of trajectory followed by young people. Thus, those that followed the late occupation (no. I), university precarious (no. II) and living with parents (no. V) types of trajectory are slow compared to the others and group $31.4 \%$ of young people. At the other extreme, both working class (no. VI and VII) types of trajectory can be considered fast, as events occur at a much earlier age than in the other groups. These groups gather $23.6 \%$ of Catalan young people. Finally, university and post-compulsory education types of trajectory (no. III and IV; 46.1\%) stand in a medium position with regard to the speed of transition. The pace of the first is certainly not quick, but for most of them there are no delays in their sub-transitions and everything happens as expected.

\section{De-linearization of Trajectories}


The second general change in youth trajectories is their de-linearization. Considering the typology of trajectories and the ages at which events happen, a relatively surprising classification can be made, as up to $63 \%$ of the young people follow linear trajectories (those in which the transitions occur following the traditional sequence of studying finding a job - leaving home - having children $^{\text {iv }}$ ). The types of trajectory counted as linear are the university linear, post-compulsory secondary education and working class trajectories (no. III, IV and VII). This result suggests that linearity is still the main pattern in the transition to adulthood in Catalonia.

On the other hand, non-linear trajectories gather $16.9 \%$ of young Catalan people (those who have followed late occupation and working class and separated from partner trajectories: no. I and VI) ${ }^{\mathrm{v}}$. Finally, $20.2 \%$ of young people follow interrupted linear trajectories (those who have university precarious or living with parents trajectories: no. II and V), in which the first sequence of transition (EducationEmployment) occurs in this traditional order but problems in the labour market make the following steps difficult or lead to them not happening.

This general classification hides, however, internal variation within each group, since -as is well known- groups resulting from cluster analysis are not totally homogenous and therefore not all individuals that form them share the same characteristics. Table 3 offers complementary data on this issue: we consider delinearization to occur when there is some inversion in the traditional sequence of transition to adulthood (Education - Employment - Housing - Family), i.e. when one sub-transition occurs before any of the previous ones in this chain (as would be the case, for example, of having children before entering the labour market). Table 3 quantifies the different types of inversions that can occur within each type of trajectory. 


\section{[TABLE 3 ABOUT HERE]}

The table confirms the low extension of de-linearization among young Catalan people's trajectories. Concerning the whole sample, Leaving home before Employment is the most frequent "sequence-inversion" but only $17.7 \%$ of the young people aged 30 34 that have already left home have followed this pattern. Employment before Education (14.8\%), Housing before Education (13.6\%) and Family before Housing $(12.9 \%)$ are the other inversions worth noting.

If we focus on the data referring to the different types of trajectory, inversion is higher in particular sub-transitions (something expected as the trajectories in this typology are often defined by these events: thus, for example, in the late occupation trajectory (no. I) leaving home occurs before occupation in $37.3 \%$ of the cases). These variations make sequence-inversion typical of two types of trajectory (late occupation and university precarious trajectories: no. I and II), while it is a minority pattern among the others. Thus, the total accumulated data shows that only $27.4 \%$ of the young people have changed the traditional sequence of events in at least one of the possibilities considered here: linear trajectories still seem to be dominant in Catalonia.

\section{Reversibility of trajectories}

The third change in youth trajectories refers to the reversibility of events, which should be expected to be the dominant pattern. Sequence-inversion occurs between subtransitions (i.e. having children before finishing studies), while reversibility occurs within each sub-transition: typical events of reversibility would be losing one's job or returning to the parental home. 


\section{[TABLE 4 ABOUT HERE]}

Table 4 highlights a number of quite relevant findings. Firstly, the accumulated figures show that $56.8 \%$ of young people aged 30-34 have experienced reversibility at least once in at least one of the sub-transitions. Secondly, reversibility (on the studied events), as could be expected, is more frequent within the Educational (32.7\%) and Employment (29.4\%) sub-transitions than within the Housing and Family ones. And thirdly, the internal logic of each trajectory explains most of the differences between them. Notably, those who follow a university precarious trajectory (no. II) tend to experience backtracking due to labour instability; those who follow a working class and separated from partner trajectory (no. VI) reverse their pathway precisely in the family dimension; and those who follow a late occupation trajectory (no. I) are likely to do so due to a mixture of events. These three types show high reversibility $(78.1 \%$ in the lower case) and gather $19.8 \%$ of young people. The other groups show a lower level of reversibility (it ranges from $59.1 \%$ to $38.1 \%$ : it is worth noting as this minimum average corresponds to the working class trajectory- no. VII).

\section{Diversification of trajectories}

The extended expansion, de-linearization and reversibility of trajectories should increase the diversity of the pathways young people can follow. However, the previous analysis suggests an ambiguous reflection on this point: on the one hand, the typology shows a wide set of possible trajectories young people may follow in their transition to 
adulthood and none of the resulting types gather more than $24 \%$ of them. Diversity, therefore, constitutes the main characteristic of the pathways followed by young people.

On the other hand, four of the trajectories gather $80.2 \%$ of young people and the total number of resulting trajectories rises only to seven. The typology is theoretically consistent and characterises quite precise, clear patterns of transition. Therefore, and despite the infinitesimal variations that may occur in each person particular pathway within each type of trajectory, there are some well established paths to follow. This becomes clearer when we consider the characteristics of the young people that follow each different trajectory: here, social origin, gender and territory may act as important predictors of the type of typology people will follow.

\section{Conclusion}

This paper has presented a typology of trajectories of transition to adulthood among young Catalan people aged 30-34. The typology is formed by seven types of trajectory (the smaller gathering $2.9 \%$ of Catalan young people and the larger 23.8\%) and ranges from privileged types of trajectories to those less favoured. As expected, social variables are not distributed evenly among the different trajectories: gender and social origin are over and underrepresented depending on the type of trajectory.

The typology itself (and some complementary data generated around it) allows us to connect young Catalan people's transitions with the current debates on changes in youth trajectories. Particularly, this paper has verified the extent to which the extension, de-linearization, reversibility and diversification of youth trajectories identified at a European level are occurring among young Catalan people. 
The results partially show these trends within Catalan society but also question the extent to which they are common features. With regard to diversification there is no dominant pattern of transition, as there are several types of trajectory, none of them gathering more than $24 \%$ of the young people; but, on the other hand, the types of trajectory identified are only seven, each of them clearly defined: hence, although diverse, pathways of transition are (objectively) well established and linked to patterns of social reproduction. The extension of the transition is a simpler issue, as the results make it clear that this is a major feature among young Catalan people, as is the case in the other Mediterranean European countries.

On the other hand, reversibility of events and de-linearization of the transition pattern are those general European tendencies that are not so clearly seen in the Catalan case. With regard to reversibility (returning to a previous stage, i.e. returning to study or to the parental home), most young people have experienced it at least once in one of the sub-transitions considered, although in few trajectories backtracking has happened in more than one sub-transition. More clearly, de-linearization is not a dominant feature and linear trajectories are by far the most common among Catalan youth: the inversion of the traditional sequence of sub-transitions is much less frequent than the usual sequence.

Probably, the Mediterranean welfare regime (Ferrara 1996) impinges on the different patterns of youth transitions identified across Europe by Walther (2006) and Van de Velde (2005), which highlight the basic role of the family in the transition into adulthood in Southern European countries. It is noticeable that Spanish young people follow a logic of "installing oneself" insofar as they often wait at the parental home until they finish their studies and get a permanent contract, and afterwards settle down on their own. Thus, the persistence of traditional patterns of transition would be the 
logical result of the particular articulation of the welfare regime and cultural patterns among young Catalan people. In a context of high uncertainty shaped by labour market segmentation and weak social policies, family support allows certain stability and the continuation of the traditional patterns of transition.

On the other hand, the (relatively unusual) types of trajectory where reversibility and de-linearization are the norm may be understood either as the involuntary outcome of the failure of the expected trajectory (as seems to be the case among the working class and separated from partner and university precarious trajectories) or as the choice of those who have been able to decide their pathway (late occupation trajectory). This finding shows how young people of a higher social origin are taking advantage of the current social changes while those with a less favourable starting position have to deal with the disadvantages.

In this sense, our results confirm Biggart and Walther's suggestion (2006) that the extension of uncertainties might demand an increasing support which, in a context of decreasing availability of formal support, will probably come from families and friends. At a European level, this may imply a certain "Mediterraneanisation" of the youth transition regime; in Southern Europe we have highlighted that it might mean the reinforcement of the traditional support families give to young people. This shows how the general trends of change in the patterns of transition among the European youth vary strongly due to the influence of the institutions that frame young people's strategies in each society, to the extent that it is not clear whether the identified tendencies are common features to all European societies. 


\section{References}

Alegre, M.A., dir, 2011. El règim de benestar juvenil a Catalunya. Barcelona, Secretaria de Joventut.

Arnett, J., 2000. Emerging adulthood: the winding road form the late teens through the twenties. American psychologist, 55 (5), 469-480.

Baizán, P., Michielin, F. and Billari, F., 2002. Political Economy and Life Course Patterns: The Heterogeneity of Occupational, Family and Household Trajectories of Young Spaniards. Demographic Research, 6 (8), 190-240.

Bauman, Z., 1992. Intimations of Postmodernity. London: Routledge.

Beck, U., 1992. Risk Society. Towards a New Modernity. London: Sage.

Biggart, A., Furlong, A. and Cartmel, F., 2008. Modern youth transitions: choice biographies and transitional linearity. In: R. Bendit and M. Hahn, eds. Youth Transitions: Process of Social Inclusion and Patterns of Vulnerability in a Globalised World. Opladen: Budrich.

Biggart, A. and Walther, A., 2006. Coping with Yo-Yo Transitions. Young Adult's Struggle for Support, between Family and State in Comparative Perspective. In: c. Leccardi and E. Ruspini, eds. A New Youth? Young people, Generations and Family Life. Aldershot: Ashgate, 41-62.

Buchmann, M., 1989. The script of life in modern society. Entry into adulthood in a changing world. Chicago: The University of Chicago Press.

Castel, R., 1995. Les métamorphoses de la question sociale: une chronique du salariat. París: Gallimard.

Cavalli, A. and Galland, O., eds., 1993. L'allongement de la jeunesse, Poitiers, Actes Sud - Observatoire du changement social.

Cavalli, A. and Galland, O., eds., 1995. Youth in Europe. London: Pinter.

Du Bois-Reymond, M., 1995. Future Orientations of Dutch Youth: The Emergence of a Choice Biography. In: A. Cavalli, and O. Galland, eds. Youth in Europe. London: Pinter, 201-222.

EGRIS, 2001. Misleading Trajectories: Transition Dilemmas for Young Adults in Europe. Journal of Youth Studies, 4 (1), 101-118.

EGRIS, 2002. Misleading Trajectories. Integration Policies for Young Adults in Europe? Opladen: Leske and Budrich.

Esping-Andersen, G., 1990. The Three Worlds of Welfare Capitalism. Cambridge: Cambridge University Press. 
Ferrara, M., 1996. The "Southern Model" of Welfare in Social Europe. Journal of European Social Policy 6 (1), 17-37.

Furlong, A. and Cartmel, F., 1997.Young People and Social Change: Individualisation and Risk in Late Modernity.Buckingham:Open University Press.

Furlong, A., Cartmel, F. Biggart, A., Sweeting, H. and West, P., 2003.Youth Transitions: Patterns of Vulnerability and Processes of Social Inclusion. Scottish Executive Social Research.

Giddens, A., 1991. Modernity and self-identity: Self and society in the late modern age. Cambridge: Polity Press.

Leccardi, C., 2006. Facing Uncertainity. Temporality and Biographies in the New Century. In: C. Leccardi and E. Ruspini, eds. A New Youth? Young People, Generations and Family Life. Aldershot: Ashgate, 15-40.

Lipovetsky, G., 1987. L'Empire de l'éphémère: la mode et son destin dans les sociétés modernes. Paris: Gallimard.

Machado, J., 2000. Transitions and youth cultures. International Social Science Journal, 164, 219-232.

Mayer, K.U., 2001. The paradox of global social change and national path dependencies. Life course patterns in advanced societies. In: Woodward, A. and Kohli, M., eds. Inclusions and exclusions in European societies. New York: Routledge, 89110 .

Mills, M., 2009. Globalization and Inequality. European Sociological Review, 25 (1), 18 .

Pollock, G., 2008. Youth Transitions: Debates over the Social Context of Becoming an Adult. Sociology Compass, 2, 467-484.

Roberts, K., 1997. Structure and Agency: The New Youth Research Agenda. In: J. Bynner, L. Chisholm and A. Furlong, eds. Youth, Citizenship and Social Change in a European Context. Aldershot: Ashgate, 57-65.

Roberts, K. et al., 2009. Young adult's family and housing life-stage transitions during post-communist transition in the South Caucasus. Journal of Youth Studies, 12 (2), 151166.

Roberts, S., 2010. Misrepresenting "choice biographies"?: a reply to Woodman. Journal of Youth Studies, 13 (1), 137-149.

Stauber, B. and Walther, A., 2002. Introduction: Young Adults in Europe - Transitions, Policies and Social Change. In: EGRIS, ed. Misleading Trajectories. Integration Policies for Young Adults in Europe? Opladen: Leske and Budrich, 11-26. 
Stauber, B. and Walther, A., 2006. De-standardised pathways to adulthood: European perspectives of informal learning on informal networks. Papers: Revista de sociologia, 79, 241-262.

Van de Velde, C., 2005. Entering adult life. A European comparison. Youth Studies Magazine, 71, 55-65.

Van de Velde, C., 2008. Devenir adulte. Sociologie comparée de la jeunesse en Europe. Paris : Presses Universitaires de France.

Walther, A., 2006. Regimes of youth transitions: Choice, flexibility and security in young people's experiences across different European contexts. Young, 14, 119-139.

Walther, A., Stauber, B. et al, eds., 2002. Misleading Trajectories: Integration Policies for Young Adults in Europe? Opladen, Leske + Budrich, 11-26,

Woodman, D., 2009. The mysterious case of the pervasive choice biography: Ulrich Beck, structure/agency and the middling state of theory on the sociology of youth. Journal of Youth Studies, 12 (3), 495-514.

i

See, for example, some of the EGRIS project outputs (EGRIS, 2001 and 2002).

ii Both researches are based on a longitudinal survey on youth transitions, use cluster analysis and give a central role to the concept of linearity, which is understood in a similar way.

The selection of variables for the cluster analysis (Table 1) does not include any variable referred to the age at which the individual starts working (usually as a secondary activity) or to the combination of studying and working.

iv Data on Education (variable: age at which the individual left formal education) from Table 2 has been complemented, in this particular analysis, with a new variable: age at which the individual first left formal education and did not return to it or did so at least after a year had passed. Thus the mean age lowers (passes from 22.0 to 19.8), especially among those university graduates that continued their studies later on. This change shows how standard educational careers finish before the first occupation (as main activity) in all groups, but for the $\mathrm{V}$, mostly formed by vocational training graduates who probably started working as part of their studies. Mean age for each type of trajectory I: 24.3 ; II: 23.2; III: 22.7; IV: 21.0; V: 18.1; VI: 16.8; VII: 15.7; Total: 19.8.

It is worth noting that in Furlong's et al (2003) research linear patterns are mostly linked to the inclusive routes while non-linear patterns tend to be more risky; our results reinforce this view but also suggest that non-linearity can sometimes be the result of the choices of some of the most advantaged young people. 